\title{
A case report of hereditary spherocytosis affecting mother and child with varied severity
}

\author{
Venkatamurthy $\mathbf{M}^{1}$, B Aditya Kumar² \\ ${ }^{1}$ Dr Venkatamurthy M, Professor, ${ }^{2}$ Dr B Aditya Kumar, Postgraduate, both authors are affiliated with Department \\ of Paediatrics, Adichunchanagiri Institute of Medical Sciences, B.G. Nagara, Nagamangala Taluk, Mandya \\ District, Karnataka, India.
}

Address for Correspondence: Dr B Aditya Kumar, E-mail: bandariaditya59@gmail.com

\begin{abstract}
Hereditary spherocytosis (HS) is a genetically transmitted form of spherocytosis, an autohemolytic anemia characterized by the production of red blood cells that are sphere-shaped rather than biconcave disc, and therefore more prone to hemolysis. It is a result of heterogeneous alterations in one of six genes (most often the ankyrin gene) that encode for proteins involved in vertical associations that tie the membrane skeleton to the lipid bilayer. We report a case of Heriditary spherocytosis affecting both mother and the baby with varied severity.
\end{abstract}

Keywords: Hereditary spherocytosis (HS), Hemolytic anemia, Autosomal Dominant.

\section{Introduction}

Hereditary spherocytosis (HS) is the most common hemolytic anemia due to a red cell membrane defect, especially in people of North European or Japanese descent, where prevalence may be as high as $1 / 5000$.It is a result of heterogeneous alterations in one of six genes (most often the ankyrin gene) that encode for proteins involved in vertical associations that tie the membrane skeleton to the lipid bilayer. Family studies indicate autosomal dominant inheritance in approximately 75 percent of patients, with recessive and spontaneous mutations occurring in most of the remaining patients [1]. Anemia, jaundice, and splenomegaly are the common clinical features of hereditary spherocytosis (HS). The degree of anemia is extremely variable and may be absent, mild, moderate, or severe to the point of threatening life [2]. The diagnosis of hereditary spherocytosis (HS) may be suspected at any age in a patient with evidence of hemolysis (eg, elevated serum lactate dehydrogenase [LDH], elevated indirect bilirubin, reduced haptoglobin).

The critical findings suggesting the diagnosis of HS as the underlying cause of the hemolysis include a positive family history of $\mathrm{HS}$, an elevated mean corpuscular hemoglobin concentration (usually $>36 \mathrm{~g} / \mathrm{dL}$ ), and the presence of spherocytes on the peripheral blood smear. Anemia and jaundice may not be present if the degree of hemolysis is minimal.

\section{Case Report}

Two and half months old male child born out of a non consanguineous marriage was brought for regular follow up, on examination baby was found to have pallor, icterus, and splenomegaly. Baby had severe anemia with $\mathrm{Hb} 4$ gm \% which required two units of blood transfusion. His peripheral smear examination showed significant amount of spherocytes (20 to 30 spherocytes per high power field) with features suggestive of hemolytic anaemia. His Direct coombs Test was negative.His Red cell variables were MCV 84fl, MCHC 36\%, MCH 32pg, Red cell Distribution Width (RDW- 15), Reticulocyte count 10.2\%. His Total Bilirubin was $6.5 \mathrm{mg} / \mathrm{dl}$, Direct bilirubin 1 $\mathrm{mg} / \mathrm{dl}$.LDH was also elevated. Babies electrolyte levels were normal. Iron Profile, Folate, HB electrophoresis

Manuscript received: $20^{\text {th }}$ March 2017

Reviewed: $30^{\text {th }}$ March 2017

Author Corrected: $9^{\text {th }}$ April 2017

Accepted for Publication: $16^{\text {th }}$ April 2017 
were done which were found normal. Osmotic Fragility started at $0.96 \%$ of $\mathrm{NaCl}$ and ended at $0.28 \%$ of $\mathrm{NaCl}$. (Markedly increased) .Other tests like eosin-5-maleimide (EMA) binding test, Acidified glycerol lysis test (AGLT), Osmotic gradient ektacytometry could not be done because of non availability at our centre and financial constraints of the patient. Baby was later discharged with Iron and Folic Acid supplementation and was asked to follow up every month to consider administering Erythropoietin (EPO) in case of severe anemia.

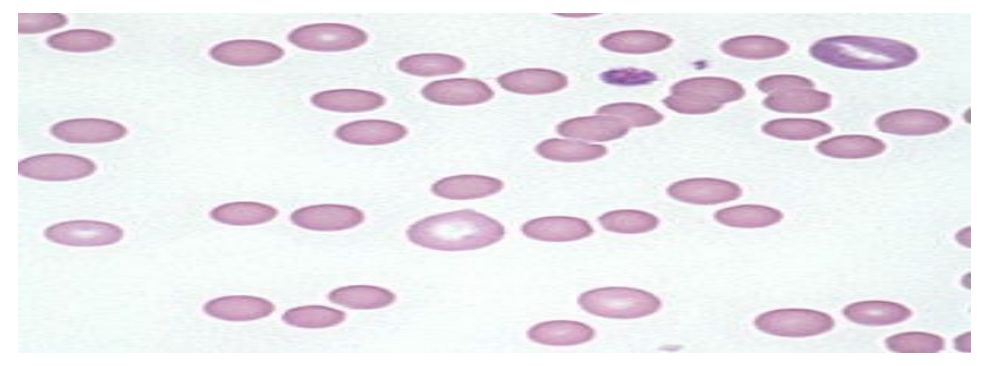

Figure-1: Periphereal smear of the child showing spherocytes

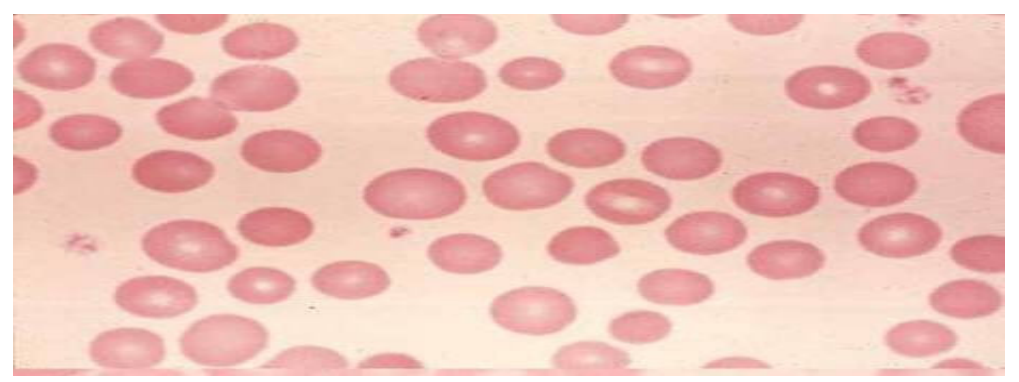

Figure-2: Periphereal smear of the mother showing spherocytes

Interestingly mother on examination was also found to have mild pallor, jaundice, splenomegaly. She never required a blood transfusion throughout her life. When investigated her $\mathrm{Hb} 9.2 \mathrm{gm} \%$, peripheral smear showed good number of spherocytes. Direct Coombs Test was negative. Her Red blood cell variables were MCV $83 \mathrm{fl}$, MCHC 37\%, Reticulocyte count 8\%. Her Total bilirubin 3.4mg/dl, Direct bilirubin $1 \mathrm{mg} / \mathrm{dl}$. Osmotic fragility started at $0.92 \%$ of $\mathrm{NaCl}$ and ended at $0.38 \%$ of $\mathrm{NaCl}$. (Markedly increased). Other confirmatory investigations could not be done due to financial reasons.

\section{Discussion}

Hereditary Spherocytosis is generally classified into three forms based upon the severity of the disease process [3]. Mild HS occurs in 20 to 30 percent of cases. These patients have no anemia, modest reticulocytosis, little in the way of splenomegaly or jaundice, and the disorder may not be detected until adolescence or adult life. Moderate HS accounts for 60 to 75 percent of cases. Moderately affected individuals are anemic, have high reticulocyte counts, and elevated serum bilirubin concentrations.

They may require occasional transfusions. Severe HS occurs in approximately 5 percent of cases. It is characterized by marked hemolysis, anemia, hyperbilirubinemia, splenomegaly, and a regular requirement for red cell transfusions.
When detected in the neonatal period, HS is commonly accompanied by jaundice, requiring treatment with phototherapy or exchange transfusion [5]. However, most neonates have little or no anemia, reticulocytosis, or spherocytosis on the peripheral blood smear $[6,7]$. This is followed by a reduction in the hemoglobin concentration over the ensuing three weeks that is transient, but may be severe enough to require transfusions [7].

Two factors are thought to be responsible for the delay in the appearance of anemia:

1. An initial failure to produce an appropriate erythropoietin response, as an adequate reticulocytosis cannot be mounted for several months after birth. 
2. Development of splenic filtering function, with progressive red blood cell trapping and destruction [7].

The diagnosis of HS is almost always made on clinical grounds, based upon the presence of spherocytes in the setting of familial hemolytic anemia and an abnormal osmotic fragility test or other screening test.

A number of tests are available for identifying individuals with HS with varying sensitivity and specificity [4].

- The sensitivity of the osmotic fragility test was 68 and 81 percent on fresh and incubated blood, respectively.

- The eosin-5-maleimide (EMA) binding test had a sensitivity and specificity of 93 and 98 percent, respectively.

- The acidified glycerol lysis test (AGLT) and Pink tests had a sensitivity and specificity of 95 and 91 percent, respectively. A combination of the EMA binding test and AGLT enabled all patients with HS to be identified.

As with most congenital hemolytic anemias, no specific treatment for the underlying red cell defect is available. Supportive care consists of the following: Folic acid supplementation, Blood transfusions, Erythropoietin, Hematopoietic stem cell transplantation and splenectomy at a later life [5].

\section{Conclusion}

The goal of the present article is to highlight that the clinical presentation of a genetic disorder can be different in the same family members depending on the gene penetration.
Funding: Nil, Conflict of interest: None initiated, Perission from IRB: Yes

\section{References}

1. Miraglia del Giudice E, Francese M, Nobili B, Morlé L, Cutillo S, Delaunay J, Perrotta S. High frequency of de novo mutations in ankyrin gene (ANK1) in children with hereditary spherocytosis. J Pediatr. 1998 Jan;132(1):117-20.

2. Perrotta S, Gallagher PG, Mohandas N. Hereditary spherocytosis. Lancet.2008 Oct 18;372 (9647):1411-26.doi:10.1016/ S0140-6736 (08) 615 88-3.

3. Bolton-Maggs PH, Stevens RF, Dodd NJ, Lamont G, Tittensor P, King MJ; General Haematology Task Force of the British Committee for Standards in Haematology. Guidelines for the diagnosis and management of hereditary spherocytosis. $\mathrm{Br} \mathrm{J}$ Haematol. 2004 Aug;126(4):455-74.

4. Kar R, Mishra P, Pati HP. Evaluation of eosin-5maleimide flow cytometric test in diagnosis of hereditary spherocytosis. Int J Lab Hematol. 2010 Feb;32 (1Pt 2):8-16. doi: 10.1111/j.1751-553X. 2008. 01098.x. Epub 2008 Sep 8.

5. Tchernia G, Delhommeau F, Perrotta S, et al. Recombinant erythropoietin therapy as an alternative to blood transfusions in infants with hereditary spherocytosis. Hematol J 2000; 1:146.

6. Schröter W, Kahsnitz E. Diagnosis of hereditary spherocytosis in newborn infants. J Pediatr. 1983 Sep; 103 (3):460-3.

7. Delhommeau F, Cynober T, Schischmanoff PO, Rohrlich P, Delaunay J, Mohandas N, Tchernia G. Natural history of hereditary spherocytosis during the first year of life. Blood.2000 Jan 15;95(2):393-7.

\section{How to cite this article?}

Venkatamurthy M, B Aditya Kumar.A case report of hereditary spherocytosis affecting mother and child with varied severity. J PediatrRes.2017;4(07):494-496.doi:10.17511/ijpr.2017.i07.10. 